\title{
Satisfying multiproduct demand with a FPR-based inventory system featuring expedited rate and scraps
}

\author{
Singa Wang Chiu ${ }^{a}$, Yi-Jing Huang ${ }^{\mathrm{b}}$, Yuan-Shyi Peter Chiu ${ }^{\mathrm{b}^{*}}$ and Tiffany Chiu ${ }^{\mathrm{c}}$
}

${ }^{a}$ Department of Business Administration, Chaoyang University of Technology, Taichung, Taiwan

${ }^{b}$ Department of Industrial Engineering \& Management, Chaoyang University of Technology, Taichung, Taiwan ${ }^{c}$ Anisfield School of Business, Ramapo College of New Jersey, Mahwah, NJ 07430, USA

\section{H R O N I C L E}

\section{Article history:}

Received October 142018

Received in Revised Format

October 282018

Accepted November 222018

Available online

November 222018

Keywords:

Multiproduct inventory system

The most economic common cycle

time

Expedited fabrication rate

Finite production rate

Random scrap

\section{A B S T R A C T}

Facing stiff competition in worldwide markets, capability of meeting timely demands of multiproduct and satisfying customer's desired product quality are essential to present-day manufacturers. Motivated by achieving the aforementioned goals, this research intends to find most economic common cycle length for a multiproduct finite production rate (FPR)-based inventory system, wherein, imperfect production process with expedited fabrication rate and random scrap is assumed. Extra setup and unit costs are associated with the adjusted rate, and imperfect products are screened and scrapped. A mathematical model is cautiously constructed to examine and resolve the problem. A numerical illustration is employed to exhibit the applicability of the proposed method. Except finding the most economic common cycle time for the problem, core contribution of this study also is associated with the individual and combined impact(s) of important factors to the problem, and hence, enabling management of manufacturing firms to make efficient/cost-effective decision and gain competitive advantages.

\section{Introduction}

This paper aims to find the most economic cycle time for a multiproduct FPR-based inventory system featuring expedited rate and scraps. The FPR model, also known as economic production quantity-EPQ model (Taft, 1918), assumed a perfect fabrication condition and focused on deciding optimal lot size which minimizes overall fabrication related costs. However, with the trend of increasing customer's needs of timely demands of multiproduct, the classic FPR model requires to be revised and expanded to meet the needs from present-day manufacturing firms. Past articles relating to diverse aspects of multiproduct inventory systems are surveyed below. Zahorik et al. (1984) considered production scheduling for multi-item multi-stage capacitated problems. For a single main facility, they proposed and examined two separate multi-item systems using linear related costs. One problem has a limitation on delivery capability, and the other one was assumed to be a bottleneck facility in the last stage of multi-stage process. Linear network programming technique was employed in their proposed

* Corresponding author Tel.: +886 4-23323000 (ext.4252)

E-mail: ypchiu@cyut.edu.tw (Y.-S.P. Chiu)

2019 Growing Science Ltd.

doi: $10.5267 / j . j$ ijiec.2018.11.001 
rolling heuristic based on a three-period result. They provided discussion on conditions where their heuristic fails to locate optimal solutions. Rosenblatt and Rothblum (1990) examined a multi-item single resource inventory problem with the objective of determining the most economic capacity to the resource of the problem. Two different common cycle length solution procedures were proposed for deciding the optimal policy. They showed the applicability of their proposed procedures through numerical examples. Clausen and Ju (2006) proposed a hybrid algorithm to resolve the economic batch size and shipping schedule problem, wherein single producer fabricates and ships different parts in batches to a buyer. The purpose of their study was mainly to decide the cycle time that keeps the annual cost minimum. Additionally, in each cycle they also determined the best fabrication sequence for different types of parts. They employed two existing algorithms, an optimal one and a heuristic from prior studies and observed their computational performances. When the size of problem is large, in terms of numerous types of parts, running time becomes long for deriving the optimal solution. Hence, a hybrid algorithm was developed by them to shorten time to locate the optimal solution. Other studies (Song, 1998; Absi \& KedadSidhoum, 2009; Ma et al., 2010; Taleizadeh et al., 2013; Chiu et al., 2016a,b; Fergany, 2016; Jawla \& Singh, 2016; Razmi et al., 2016; Zahedi et al., 2016; Vujosevic et al., 2017; Chiu et al., 2018a) also focused on diverse subjects of multiproduct stock refilling systems.

To reduce fabrication completion time a commonly used strategy is to expedite manufacturing rate. Villeda et al. (1988) considered a just-in-time (JIT) system that has kanbans of three assembly lines merging into a final station of the assembly. The times for operations are varied, and the impacts of variability can be decreased by increasing level of work-in-process (WIP) or by unbalancing three assembly lines via work assignment at each station. They analyzed different unbalancing approaches to find out that unbalanced stations have a consistent output rate improvement for the proposed JIT system and these rates outperformed that of the perfectly balanced stations. They also discussed the extent of output rate improvement and their relationship with the inter-stage buffer capacities of the system. Larsen (1997) reexamined a well known economic production lot-size problem and treated the manufacturing rate as a decision variable. His study pointed out an interesting finding that was in response to an increased demand rate, the mechanism of decreasing manufacturing rate can be optimal. Pellerin et al. (2009) studied fabrication rate control problem for stochastic remanufacturing and repair systems. They first formulated the system as a multi-level control problem, then, proposed a suboptimal control policy, which uses inventory thresholds to activate distinct control executing modes. Parameters of control policy are decided according to optimization of analytical cost equations. A real numerical case is applied to confirm the applicability of their controlling approach, which leads to a major savings in total cost as compared with a system without employing the control policy. Glock (2013) demonstrated that applying random shifts in machine fabrication rate, for instance, in the case of technical defects, may lead to a decline in cost, and hence, an increase in profit. Inspired by this idea, he used an existing inventory model to demonstrate how it works and traced it back to ordinary assumptions made in the literature. Extra studies (Wolisz, 1984; Gallego, 1993; Bylka \& Rempala, 2001; Neidigh \& Harrison, 2010; Muller \& Clarkson, 2016; Rakyta et al., 2016; Liu et al., 2017; Kumar et al., 2017; Ameen et al., 2018; Chiu et al., 2018b,c) also addressed different issues and effects on systems with variable production rates.

Further, due to diverse unexpected/uncontrollable factors in manufacturing environments, fabrication of scrap items is inevitable. Rosenblatt and Lee (1986) investigated the impact of imperfect manufacturing process on the economic fabrication cycle time. The process is first assumed to be in-control, and it may randomly switch to outof-control state and causes fabrication of a fixed proportion of defective products. They proposed approximate solution procedures to locate optimal lot-size for the problem. Cheung and Hausman (1997) examined a fabrication system with stochastic equipment failures, with the objective of simultaneously determining best policies for preventive maintenance and safety stock. Cost-effectiveness of investment on these policies were explored and discussed. Both exponential and deterministic repair time distributions were assumed and analyzed. The resulting optimal conditions that minimize relating costs under either one or both policies are found respectively. Maddah et al. (2010) studied a production- inventory model with random supply. They assumed that the fabrication process may shift to out-of-control state under a constant probability, and begin to produce defective items. Two separate models were explored with different policies for handling the defects: (1) removal of defects from the inventory at no disposal cost, and (2) defective items are consolidated as batches and there is a disposal cost in removing/shipping them. Both models were studied to discover the optimal lot-size and expected system cost, respectively. Other research focused on diverse imperfect features of manufacturing systems can also be found (e.g. Makis, 1998; Eroglu \& Ozdemir, 2007; Chakraborty et al., 2013; Kaylani et al., 2016; Majumder et al., 2016; Zhang et al., 2016; Khanna et al., 2017; Rezazadeh \& Khiali-Miab, 2017; Shakoor et al., 2017; Al-Bahkali \& 
Abbas, 2018; Pearce et al., 2018). Because few studies focuse on multiproduct fabrication system by considering an expedited rate and scraps, this research aims to fill the gap.

\section{The FPR-based multiproduct inventory system with expedited rate and scraps}

A finite production rate (FPR)-based multiproduct inventory system featuring expedited rate and random scraps is investigated. Unlike conventional FPR model, the proposed system adopts an expedited rate to reduce cycle time of the batch fabrication, and also examines the effect of random defective (scrap) items on optimal lot-size decision. Let $L$ be diverse products with demand rates $\lambda_{i}$ per year (where $i=1,2, \ldots, L$ ), which must be satisfied by a production equipment that has an expedited manufacturing rate $P_{1 i \mathrm{~A}}$ under common fabrication cycle time principle (Fig. 1). Manufacturing processes are imperfect a $x_{i}$ portion of random scrap is produced during the processes (Fig. 2) at a rate of $d_{1 \mathrm{iA}}$ as follows:

$$
d_{1 i \mathrm{~A}}=x_{i} P_{1 i \mathrm{~A}}
$$

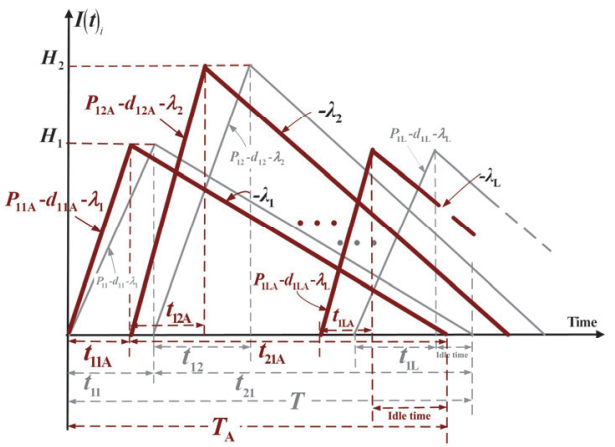

Fig. 1. Level of finished item $i$ in the proposed FPR-based multiproduct inventory system with expedited rate and scraps (in red) as compared to the same system with standard rate (in grey)

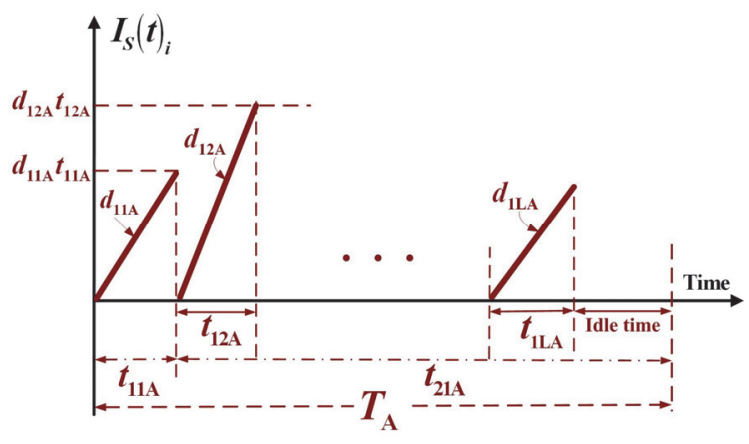

Fig. 2. Level of scrapped product $i$ in the proposed FPRbased multiproduct inventory system with expedited rate and scraps

The following requirement must be satisfied to make sure that the production equipment has sufficient capacity to fabricate $L$ products (Nahmias, 2009):

$$
\sum_{i=1}^{L}\left\{\frac{\lambda_{i}}{\left[1-E\left[x_{i}\right]\right] P_{1 \text { iA }}}\right\}<1
$$

where $\mathrm{E}\left[x_{i}\right]$ denotes the expected random scrap rate of product $i$. Further, shortages are not permitted in the proposed system, so for each product $i$, the following equation must hold to avoid the unwanted stock-out occurrences in the proposed batch production planning:

$$
P_{1 i \mathrm{~A}}-d_{1 i \mathrm{~A}}-\lambda_{i}>0 \text {. }
$$

Additional notations also include:

$Q_{i}=$ batch size per cycle of product $i$,

$T_{\mathrm{A}}=$ common production cycle time with expedited rate - the decision variable,

$P_{1 i \mathrm{~A}}=$ expedited manufacturing rate of product $i$ per unit time (year),

$P_{1 i}=$ standard manufacturing rate of product $i$ per unit time,

$\alpha_{1 i}=$ expedited proportion of manufacturing rate (where $\alpha_{1 i}>0$ ),

$C_{i \mathrm{~A}}=$ unit cost of product $i$ with expedited rate,

$C_{i}=$ standard unit cost of product $i$ without expedited rate,

$\alpha_{3 i}=$ added cost (between $C_{i \mathrm{~A}}$ and $C_{i}$ ) due to expedited rate (where $\alpha_{3 i}>0$ ),

$K_{i \mathrm{~A}}=$ setup cost of product $i$ with expedited rate,

$K_{i}=$ standard setup cost of product $i$,

$\alpha_{2 i}=$ relating factor between $K_{i \mathrm{~A}}$ and $K_{i}$ (where $\alpha_{2 i}>0$ ),

$t_{1 \mathrm{iA}}=$ uptime of product $i$ with expedited rate,

$t_{2 i \mathrm{~A}}=$ downtime time of product $i$,

$h_{i}=$ unit holding cost of product $i$,

$C_{\mathrm{S} i}=$ disposal charge per scrapped product $i$,

$H_{i}=$ level of finished item $i$ at uptime completion,

$T=$ common production cycle time in the same system without expedited rate, 
$t_{1 i}=$ uptime of product $i$ in the same system without expedited rate,

$t_{2 i}=$ downtime of product $i$ in the same system without expedited rate,

$d_{1 i}=$ production rate of scrapped product $i$ in the same system without expedited rate,

$\mathrm{E}\left[T_{\mathrm{A}}\right]=$ the expected common production cycle time,

$I(t)_{i}=$ level of finished item $i$ at time $t$,

$I_{\mathrm{S}}(t)_{i}=$ level of scrapped item $i$ at time $t$,

$T C\left(T_{\mathrm{A}}\right)=$ total system cost in a cycle,

$\mathrm{E}\left[\operatorname{TCU}\left(T_{\mathrm{A}}\right)\right]=$ expected system cost per unit time,

$\overline{P_{1 \mathrm{~A}}}=$ the average of $P_{1 \mathrm{~A}}$,

$\overline{P_{1}}=$ the average of $P_{1 i}$,

$\bar{x}=$ the average of $x_{i}$,

$\overline{C_{\mathrm{A}}}=$ the average of $C_{i \mathrm{~A}}$,

$\bar{C}=$ the average of $C_{i}$,

$\overline{\alpha_{1}}=$ the average of $\alpha_{1 i}$,

$\overline{\alpha_{2}}=$ the average of $\alpha_{2 i}$,

$\overline{\alpha_{3}}=$ the average of $\alpha_{3 i}$.

Since expedited rate has been incorporated into the proposed multiproduct FPR-based system, certain distinct relationships between relevant system parameters are assumed as follows:

$$
\begin{aligned}
& P_{1 i \mathrm{~A}}=\left(1+\alpha_{1 i}\right) P_{1 i} \\
& C_{i \mathrm{~A}}=\left(1+\alpha_{3 i}\right) C_{i} \\
& K_{i \mathrm{~A}}=\left(1+\alpha_{2 i}\right) K_{i}
\end{aligned}
$$

The following formulas can also be undoubtedly observed from Figs. (1-2):

$$
\begin{aligned}
& t_{1 i \mathrm{~A}}=\frac{Q_{i}}{P_{1 i \mathrm{~A}}} \\
& t_{2 i \mathrm{~A}}=\frac{H_{i}}{\lambda_{i}} \\
& T_{\mathrm{A}}=t_{1 i \mathrm{~A}}+t_{2 i \mathrm{~A}} \\
& H_{i}=\left(P_{1 i \mathrm{~A}}-d_{1 i \mathrm{~A}}-\lambda_{i}\right) t_{1 i \mathrm{~A}} \\
& Q_{i}=\frac{\lambda_{i} T_{\mathrm{A}}}{\left[1-E\left[x_{i}\right]\right]} . \\
& d_{1 i \mathrm{~A}} t_{1 i \mathrm{~A}}=x_{i} P_{1 i \mathrm{~A}} t_{1 i \mathrm{~A}}=x_{i} Q_{i} .
\end{aligned}
$$

\section{Cost analysis and optimization}

Total system cost in a cycle $-T C\left(\mathrm{~T}_{\mathrm{A}}\right)$ contains: (1) the sum of setup and variable manufacturing costs for $L$ products; (2) the sum of disposal costs, and (3) and the sum of holding costs for $L$ products as follows:

$$
\begin{aligned}
& \sum_{i=1}^{L}\left[K_{i \mathrm{~A}}+C_{i \mathrm{~A}} Q_{i}+C_{\mathrm{S} i}\left(x_{i} Q_{i}\right)\right]=\sum_{i=1}^{L}\left[\left(1+\alpha_{2 i}\right) K_{i}+\left(1+\alpha_{3 i}\right) C_{i} Q_{i}+C_{\mathrm{S} i}\left(x_{i} Q_{i}\right)\right] \\
& \sum_{i=1}^{L}\left[C_{\mathrm{S} i}\left(x_{i} Q_{i}\right)\right] \\
& \sum_{i=1}^{L}\left\{h_{i}\left[\frac{H_{i}+d_{1 i \mathrm{~A}} t_{1 i \mathrm{~A}}}{2}\left(t_{1 i \mathrm{~A}}\right)+\frac{H_{i}}{2}\left(t_{2 i \mathrm{~A}}\right)\right]\right\} .
\end{aligned}
$$

Hence, $T C\left(T_{\mathrm{A}}\right)$ is the following: 


$$
T C\left(T_{\mathrm{A}}\right)=\sum_{i=1}^{L}\left\{\left(1+\alpha_{2 i}\right) K_{i}+\left(1+\alpha_{3 i}\right) C_{i} Q_{i}+C_{\mathrm{Si}}\left(x_{i} Q_{i}\right)+h_{i}\left[\frac{H_{i}+d_{1 i \mathrm{~A}} t_{1 i \mathrm{~A}}}{2}\left(t_{1 \mathrm{~A}}\right)+\frac{H_{i}}{2}\left(t_{2 i \mathrm{~A}}\right)\right]\right\} .
$$

We use $E\left[x_{i}\right]$ to handle the randomness of $x_{i}$, substitute Eqs. (4-12) in Eq. (16), and with extra efforts on derivations, $\mathrm{E}\left[\operatorname{TCU}\left(T_{\mathrm{A}}\right)\right]$ to find the following,

$$
\begin{aligned}
E[T C U & \left.\left(T_{\mathrm{A}}\right)\right]=\frac{E\left[T C\left(T_{\mathrm{A}}\right)\right]}{E\left[T_{\mathrm{A}}\right]} \\
& =\sum_{i=1}^{L}\left\{\frac{\left(1+\alpha_{2 i}\right) K_{i}}{T_{\mathrm{A}}}+\frac{\left(1+\alpha_{3 i}\right) C_{i} \lambda_{i}}{1-E\left[x_{i}\right]}+\frac{C_{\mathrm{S} i} E\left[x_{i}\right] \lambda_{i}}{1-E\left[x_{i}\right]}+\frac{h_{i} T_{\mathrm{A}} \lambda_{i}}{2}\left[1+\frac{\lambda_{i}\left[2 E\left[x_{i}\right]-1\right]}{\left[1-E\left[x_{i}\right]\right]^{2}\left(1+\alpha_{1 i}\right) P_{1 i}}\right]\right\} .
\end{aligned}
$$

\subsection{Deciding optimal common production cycle time}

The first- and second-derivative of $E\left[T C U\left(T_{\mathrm{A}}\right)\right]$ are as follows:

$$
\begin{aligned}
& \frac{d E\left[T C U\left(T_{\mathrm{A}}\right)\right]}{d T_{\mathrm{A}}}=\sum_{i=1}^{L}\left\{\frac{-\left(1+\alpha_{2 i}\right) K_{i}}{T_{\mathrm{A}}{ }^{2}}+\frac{h_{i} \lambda_{i}}{2}\left[1+\frac{\lambda_{i}\left[2 E\left[x_{i}\right]-1\right]}{\left[1-E\left[x_{i}\right]\right]^{2}\left(1+\alpha_{1 i}\right) P_{1 i}}\right]\right\} \\
& \frac{d^{2} E\left[T C U\left(T_{\mathrm{A}}\right)\right]}{d T_{\mathrm{A}}{ }^{2}}=\sum_{i=1}^{L}\left\{\frac{2\left(1+\alpha_{2 i}\right) K_{i}}{T_{\mathrm{A}}{ }^{3}}\right\} .
\end{aligned}
$$

For $\left(1+\alpha_{2 i}\right), T_{\mathrm{A}}$, and $K_{i}$ are all positive and we confirm that the second-derivative of $E\left[T C U\left(T_{\mathrm{A}}\right)\right]$ (Eq. (19)) is positive. Hence, $E\left[T C U\left(T_{\mathrm{A}}\right)\right]$ is convex for all $T_{\mathrm{A}}$ other than zero. To find the optimal $T_{\mathrm{A}}{ }^{*}$, one can set the firstderivative of $E\left[T C U\left(T_{\mathrm{A}}\right)\right]=0$ and solve the following:

$$
\frac{d E\left[\operatorname{TCU}\left(T_{\mathrm{A}}\right)\right]}{d T_{\mathrm{A}}}=\sum_{i=1}^{L}\left\{\frac{-\left(1+\alpha_{2 i}\right) K_{i}}{T_{\mathrm{A}}^{2}}+\frac{h_{i} \lambda_{i}}{2}\left[1+\frac{\lambda_{i}\left[2 E\left[x_{i}\right]-1\right]}{\left[1-E\left[x_{i}\right]\right]^{2}\left(1+\alpha_{1 i}\right) P_{1 i}}\right]\right\}=0 .
$$

The following optimal $T_{\mathrm{A}} *$ can be found after extra derivations:

$$
T_{\mathrm{A}}^{*}=\sqrt{\frac{2 \sum_{i=1}^{L}\left[\left(1+\alpha_{2 i}\right) K_{i}\right]}{\sum_{i=1}^{L}\left[h_{i} \lambda_{i}\left(1+\frac{\lambda_{i}\left[2 E\left[x_{i}\right]-1\right]}{\left[1-E\left[x_{i}\right]\right]^{2}\left(1+\alpha_{1 i}\right) P_{1 i}}\right)\right]}} .
$$

Finally, it should be noted that total setup times of $L$ products may affect the aforementioned optimal cycle time if it cannot be accommodated in idle time of the proposed system (see Fig. 1 for idle time). If this is the case, then one should calculate the following $T_{\min }$ (Nahmias, 2009) and choose $\max \left(T_{\mathrm{A}}{ }^{*}, T_{\min }\right)$ as the cycle length $T_{\mathrm{A}}$ in order to assure that cycle length can contain the sum of setup times:

$$
T_{\min }=\frac{\sum_{i=1}^{L}\left(S_{i}\right)}{1-\sum_{i=1}^{L}\left[\frac{\lambda_{i}}{\left[1-E\left[x_{i}\right]\right] P_{1 i \mathrm{~A}}}\right]} .
$$

\section{Numerical example}

Suppose demands of 5 products need to be satisfied by a FPR-based inventory system with expedited manufacturing rate and random scrap rate. Assumptions of system's variables are listed in Table 1. 
Table 1

Assumptions of system's variables

\begin{tabular}{ccccccccccccccccccc}
\hline $\begin{array}{c}\text { Product } \\
\text { number }\end{array}$ & $\lambda_{i}$ & $C_{i}$ & $K_{i}$ & $h_{i}$ & $x_{i}$ & $C_{\mathrm{S} i}$ & $P_{1 i}$ & $\alpha_{1 i}$ & $\alpha_{2 i}$ & $\alpha_{3 i}$ & $P_{1 i \mathrm{~A}}$ & $K_{i \mathrm{~A}}$ & $C_{i \mathrm{~A}}$ \\
\hline 1 & 3000 & 80 & 10000 & 10 & $5 \%$ & 20 & 58000 & 0.30 & 0.06 & 0.15 & 75400 & 10600 & 92 \\
2 & 3200 & 90 & 11000 & 15 & $10 \%$ & 25 & 59000 & 0.40 & 0.08 & 0.20 & 82600 & 11880 & 108 \\
3 & 3400 & 100 & 12000 & 20 & $15 \%$ & 30 & 60000 & 0.50 & 0.10 & 0.25 & 90000 & 13200 & 125 \\
4 & 3600 & 110 & 13000 & 25 & $20 \%$ & 35 & 61000 & 0.60 & 0.12 & 0.30 & 97600 & 14560 & 143 \\
5 & 3800 & 120 & 14000 & 30 & $25 \%$ & 40 & 62000 & 0.70 & 0.14 & 0.35 & 105400 & 15960 & 162 \\
\hline
\end{tabular}

To start with numerical demonstration, we first calculate Eq. (21) and Eq. (17) and find $T_{\mathrm{A}} *=0.6262$ and $E\left[\operatorname{TCU}\left(T_{\mathrm{A}}^{*}\right)\right]=\$ 2,608,056$.

Table 2 exhibits the analytical effects of changes in average expedited proportion of manufacturing rate $\overline{\alpha_{1}}$ on major parameters of the proposed based system. From Table 2, the quality cost (due to the existence of random scrap rate in manufacturing processes) is $\$ 208,724$, which is about $8.00 \%$ of system cost $E\left[T C U\left(T_{\mathrm{A}} *\right)\right]$. Moreover, the exploratory result on effect of changes in average random scrap rate $\bar{x}$ on total disposal cost is illustrated in Fig. 3. It shows that total disposal cost raises notably, as $\bar{x}$ increases; and at $\bar{x}=0.15$ (as assumed in this example), total disposal cost is $\$ 49,734$.

Table 2

Analytical effects of changes in $\overline{\alpha_{1}}$ on major parameters of the proposed system

\begin{tabular}{|c|c|c|c|c|c|c|c|c|c|c|c|c|c|}
\hline$\alpha_{1}$ & $T_{\mathrm{A}} *$ & $\alpha_{3}$ & $\begin{array}{l}\text { Sum of } \\
\text { variable } \\
\text { cost (1) }\end{array}$ & $\begin{array}{l}\%(1) / \\
\text { (3) }\end{array}$ & $\begin{array}{c}\% \\
\text { increase }\end{array}$ & $\begin{array}{c}\text { Sum of } \\
\text { quality cost } \\
\text { (2) }\end{array}$ & $\begin{array}{l}\%(2) / \\
\text { (3) }\end{array}$ & $\begin{array}{l}\text { Sum of } \\
\text { setup } \\
\text { cost }\end{array}$ & $\begin{array}{c}\text { Sum of } \\
\text { holding } \\
\text { cost }\end{array}$ & $\begin{array}{c}E\left[T C U\left(T_{\mathrm{A}} *\right)\right] \\
(3)\end{array}$ & $\begin{array}{c}\% \\
\text { increase }\end{array}$ & $\begin{array}{l}\text { Sum of } \\
\text { utilization }\end{array}$ & $\begin{array}{l}\% \text { drop in } \\
\text { utilization }\end{array}$ \\
\hline 0.00 & 031 & 0.00 & $\$ 1,720,000$ & $80.88 \%$ & $00 \%$ & $\$ 209,154$ & $9.83 \%$ & $\$ 99,489$ & $\$ 98,090$ & $\$ 2,126,734$ & $0.00 \%$ & 0.3070 & - \\
\hline 0.10 & 0.6074 & 0.05 & $\$ 1,813,901$ & $81.59 \%$ & $5.46 \%$ & $\$ 209,036$ & $9.40 \%$ & $\$ 100,756$ & $\$ 99,476$ & $\$ 2,223,169$ & $4.53 \%$ & 0.2791 & $-9.09 \%$ \\
\hline 0.20 & 0.6119 & 0.10 & $\$ 1,907,802$ & $82.25 \%$ & $10.92 \%$ & $\$ 208,938$ & $9.01 \%$ & $\$ 101,972$ & $\$ 100,789$ & $\$ 2,319,502$ & $9.06 \%$ & 0.2559 & $-16.67 \%$ \\
\hline 0.30 & 0.6166 & 0.15 & $\$ 2,001,703$ & $82.86 \%$ & $16.38 \%$ & $\$ 208,856$ & $8.65 \%$ & $\$ 103,146$ & $\$ 102,046$ & $\$ 2,415,752$ & $13.59 \%$ & 0.2362 & $-23.08 \%$ \\
\hline 0.40 & 0.6214 & 0.20 & $\$ 2,095,604$ & $83.43 \%$ & $21.84 \%$ & $\$ 208,785$ & $8.31 \%$ & $\$ 104,286$ & $\$ 103,257$ & $\$ 2,511,933$ & $18.11 \%$ & 0.2193 & $-28.57 \%$ \\
\hline 0.50 & 0.6262 & 0.25 & $\$ 2,189,506$ & $83.95 \%$ & $27.30 \%$ & $\$ 208,724$ & $8.00 \%$ & $\$ 105,397$ & $\$ 104,429$ & $\$ 2,608,056$ & $22.63 \%$ & 0.2047 & $-33.33 \%$ \\
\hline 0.60 & 0.6311 & 0.30 & $\$ 2,283,407$ & $84.44 \%$ & $32.76 \%$ & $\$ 208,671$ & $7.72 \%$ & $\$ 106,483$ & $\$ 105,568$ & $\$ 2,704,128$ & $27.15 \%$ & 1919 & $-37.50 \%$ \\
\hline 0.70 & 0.6360 & 0.35 & $\$ 2,377,308$ & $84.90 \%$ & $38.22 \%$ & $\$ 208,623$ & $7.45 \%$ & $\$ 107,547$ & $\$ 106,679$ & $\$ 2,800,157$ & $31.66 \%$ & 1806 & $-41.18 \%$ \\
\hline 0.80 & 0.6409 & 0.40 & $\$ 2,471,209$ & $85.33 \%$ & $43.67 \%$ & $\$ 208,582$ & $7.20 \%$ & $\$ 108,591$ & $\$ 107,765$ & $\$ 2,896,147$ & $36.18 \%$ & 0.1706 & $-44.44 \%$ \\
\hline 0.90 & 0.6459 & 0.45 & $\$ 2,565,110$ & $85.73 \%$ & $49.13 \%$ & $\$ 208,544$ & $6.97 \%$ & $\$ 109,618$ & $\$ 108,830$ & $\$ 2,992,102$ & $40.69 \%$ & 0.1616 & $-47.37 \%$ \\
\hline 1.00 & 0.6508 & 0.50 & $\$ 2,659,011$ & $86.11 \%$ & $54.59 \%$ & $\$ 208,510$ & $6.75 \%$ & $\$ 110,629$ & $\$ 109,874$ & $\$ 3,088,025$ & $45.20 \%$ & 0.1535 & $-50.00 \%$ \\
\hline 1.10 & 0.6558 & 0.55 & $\$ 2,752,912$ & $86.46 \%$ & $60.05 \%$ & $\$ 208,480$ & $6.55 \%$ & $\$ 111,626$ & $\$ 110,901$ & $\$ 3,183,919$ & $49.71 \%$ & 0.1462 & $-52.38 \%$ \\
\hline 1.20 & 0.6607 & 0.60 & $\$ 2,846,813$ & $86.80 \%$ & $65.51 \%$ & $\$ 208,452$ & $6.36 \%$ & $\$ 112,609$ & $\$ 111,912$ & $\$ 3,279,786$ & $54.22 \%$ & 0.1396 & $-54.55 \%$ \\
\hline 1.30 & 0.6656 & 0.65 & $\$ 2,940,714$ & $87.12 \%$ & $70.97 \%$ & $\$ 208,427$ & $6.17 \%$ & $\$ 113,579$ & $\$ 112,908$ & $\$ 3,375,628$ & $58.72 \%$ & 0.1335 & $-56.52 \%$ \\
\hline 1.40 & 0.6705 & 0.70 & $\$ 3,034,616$ & $87.42 \%$ & $76.43 \%$ & $\$ 208,404$ & $6.00 \%$ & $\$ 114,538$ & $\$ 113,890$ & $\$ 3,471,447$ & $63.23 \%$ & 0.1279 & $-58.33 \%$ \\
\hline 1.50 & 0.6754 & 0.75 & $\$ 3,128,517$ & $87.70 \%$ & $81.89 \%$ & $\$ 208,382$ & $5.84 \%$ & $\$ 115,486$ & $\$ 114,859$ & $\$ 3,567,244$ & $67.73 \%$ & 0.1228 & $-60.00 \%$ \\
\hline 1.60 & 0.6803 & 0.80 & $\$ 3,222,418$ & $87.97 \%$ & $87.35 \%$ & $\$ 208,363$ & $5.69 \%$ & $\$ 116,423$ & $\$ 115,816$ & $\$ 3,663,020$ & $72.24 \%$ & 0.1181 & $-61.54 \%$ \\
\hline 1.70 & 0.6851 & 0.85 & $\$ 3,316,319$ & $88.23 \%$ & $92.81 \%$ & $\$ 208,344$ & $5.54 \%$ & $\$ 117,351$ & $\$ 116,762$ & $\$ 3,758,776$ & $76.74 \%$ & 0.1137 & $-62.96 \%$ \\
\hline 1.80 & 0.6900 & 0.90 & $\$ 3,410,220$ & $88.47 \%$ & $98.27 \%$ & $\$ 208,327$ & $5.40 \%$ & $\$ 118,269$ & $\$ 117,698$ & $\$ 3,854,514$ & $81.24 \%$ & 0.1097 & $-64.29 \%$ \\
\hline 1.90 & 0.6948 & 0.95 & $\$ 3,504,121$ & $88.71 \%$ & $103.73 \%$ & $\$ 208,311$ & $5.27 \%$ & $\$ 119,179$ & $\$ 118,623$ & $\$ 3,950,234$ & $85.74 \%$ & 0.1059 & $-65.52 \%$ \\
\hline 2.00 & 0.6995 & 1.00 & $\$ 3,598,022$ & $88.93 \%$ & $109.19 \%$ & $\$ 208,297$ & $5.15 \%$ & $\$ 120,079$ & $\$ 119,539$ & $\$ 4,045,937$ & $90.24 \%$ & 0.1023 & $-66.67 \%$ \\
\hline
\end{tabular}

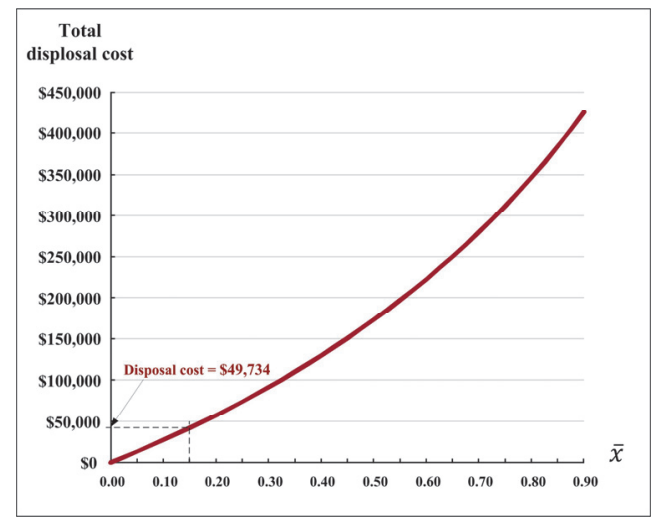

Fig. 3. Effect of changes in average random scrap rate $\bar{x}$ on total disposal cost

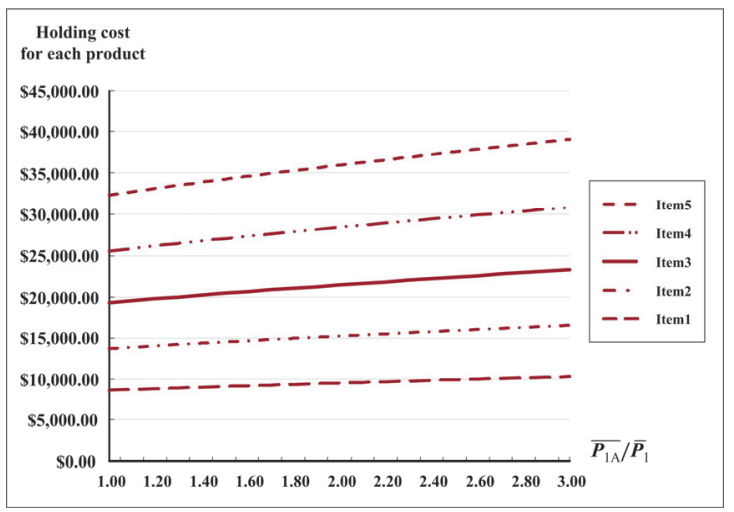

Fig. 4. Impact of differences in $\overline{P_{1 \mathrm{~A}}} / \overline{P_{1}}$ on the holding cost for each product 
Fig. 4 depicts the impact of differences in ratio of average expedited manufacturing rate over average standard production rate $\overline{P_{1 \mathrm{~A}}} / \overline{P_{1}}$ on the holding cost for each product. It indicates that holding cost for each product increases mildly, as the ratio of $\overline{P_{1 \mathrm{~A}}} / \overline{P_{1}}$ increases. The influences of variations in common cycle time $T_{\mathrm{A}}$ on $E\left[T C U\left(T_{\mathrm{A}}\right)\right]$ and its different cost factors are examined and displayed in Fig. 5. It indicates that $E\left[T C U\left(T_{\mathrm{A}}\right)\right]$ increases significantly, as $T_{\mathrm{A}}$ deviates from $T_{\mathrm{A}} *(=0.6262)$; and as $T_{\mathrm{A}}$ goes up, quality cost rises slightly and holding cost increases a lot, in contrast, setup cost declines radically. Further, $T_{\mathrm{A}}{ }^{*}=0.6262$ has been verified along with $E\left[T C U\left(T_{\mathrm{A}}{ }^{*}\right)\right]=$ $\$ 2,608,056$.

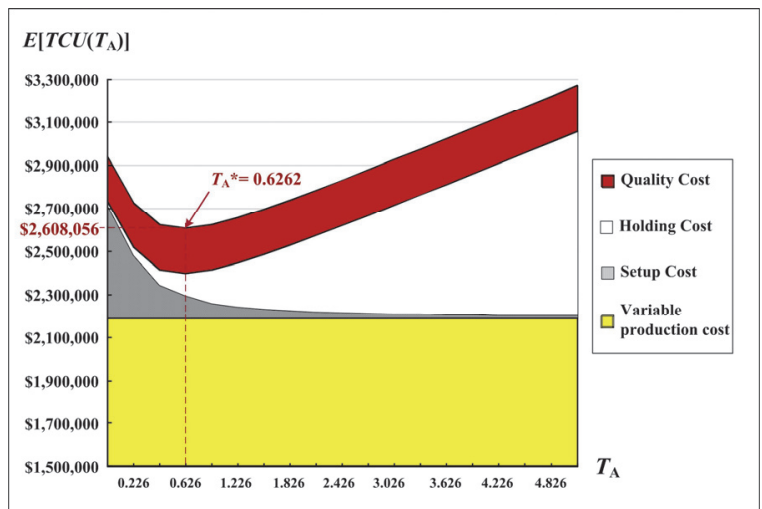

Fig. 5. Influences of variations in $T_{\mathrm{A}}$ on $E\left[T C U\left(T_{\mathrm{A}}\right)\right]$ and its different cost factors

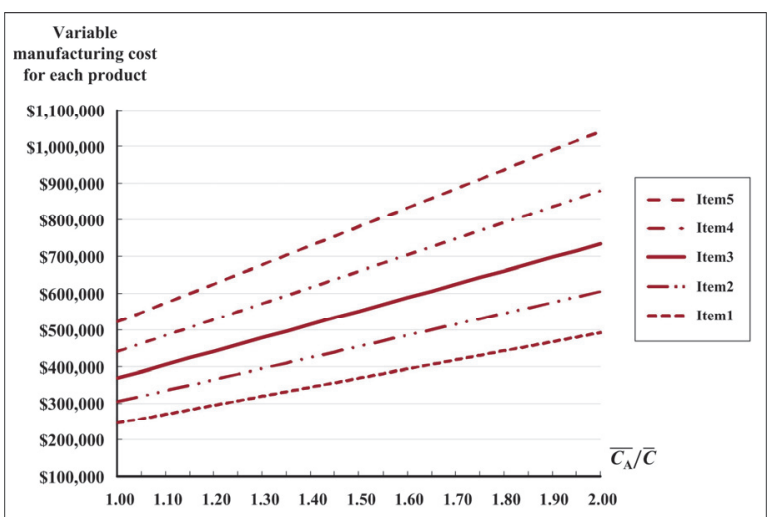

Fig. 6. Impact of variations in ratio of $\overline{C_{\mathrm{A}}} / \bar{C}$ on variable manufacturing cost for each product

Fig. 6 shows the impact of variations in ratio of average expedited unit cost over average standard unit $\operatorname{cost} \overline{C_{\mathrm{A}}} /$ $\bar{C}$ on variable manufacturing cost for each product. It is noted that variable manufacturing cost for each product notably increases, as the ratio of $\overline{C_{\mathrm{A}}} / \bar{C}$ rises. Influences of changes in ratio of $\overline{P_{1 \mathrm{~A}}} / \overline{P_{1}}$ on the sum of machine utilization are illustrated in Fig. 7. It points out that sum of utilization drops significantly, as $\overline{P_{1 \mathrm{~A}}} / \overline{P_{1}}$ ratio rises; and the sum of utilization declines to 0.2047 (from 0.3070, for details refer to Table 2) when $\overline{P_{1 \mathrm{~A}}} / \overline{P_{1}}=1.5$ (as in our example).

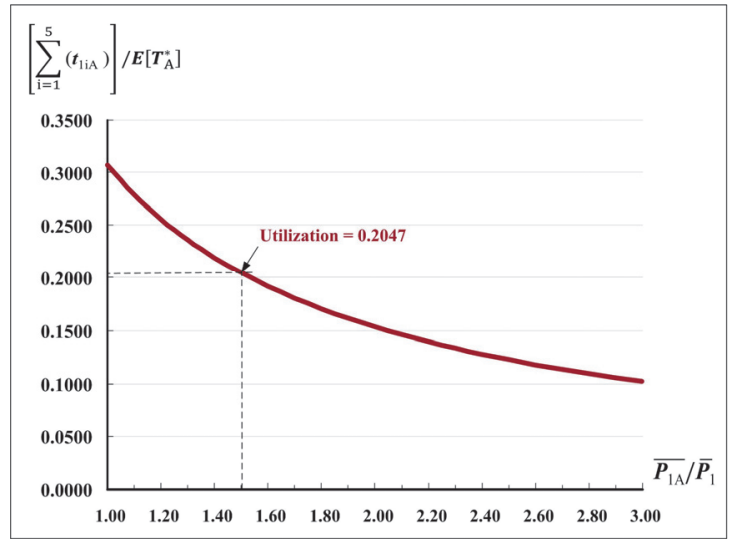

Fig. 7. Impact of changes in $\overline{P_{1 \mathrm{~A}}} / \overline{P_{1}}$ ratio on sum of utilization

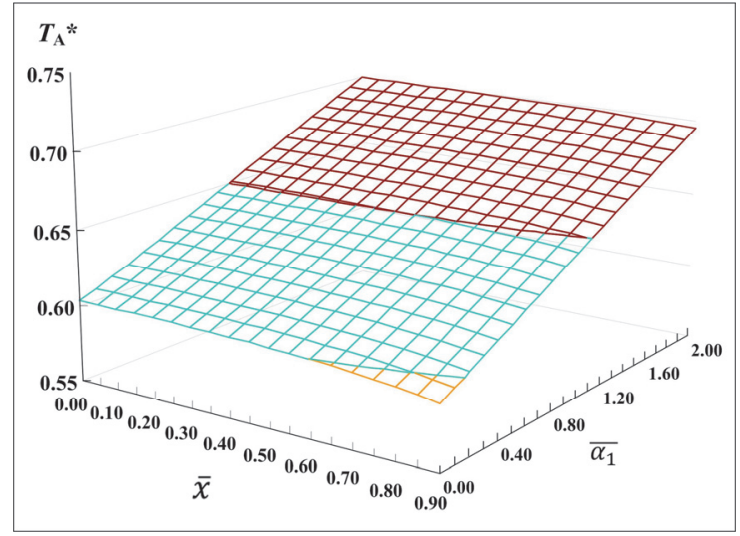

Fig. 8. Joint effects of differences in $\bar{x}$ and $\overline{\alpha_{1}}$ on $T_{\mathrm{A}} *$

Fig. 8 depicts the exploratory outcomes on combined effects of differences in $\bar{x}$ and average expedited proportion of manufacturing rate $\overline{\alpha_{1}}$ on $T_{\mathrm{A}}{ }^{*}$. It indicates that $T_{\mathrm{A}} *$ slightly decreases, as $\bar{x}$ raises; and conversely, $T_{\mathrm{A}} *$ increases radically, as $\bar{\alpha}_{1}$ goes up. Investigative result on distinctive cost elements in the proposed FPR system is presented in Fig. 9. It shows that quality cost (due to random scrap) contributes $8.00 \%$ to $E\left[T C U\left(T_{\mathrm{A}}{ }^{*}\right)\right]$, and sum of variable manufacturing cost is $83.95 \%$ of $E\left[T C U\left(T_{\mathrm{A}}{ }^{*}\right)\right]$ due to the added cost from the expedited manufacturing policy used (an increase of $25 \%$ as compared to when $\overline{\alpha_{1}}=0$, see Table 2). 


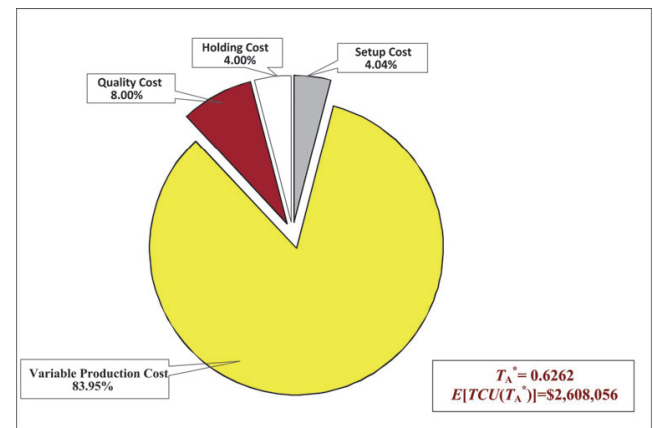

Fig. 9. Investigative result on distinctive cost elements in the proposed FPR-based system

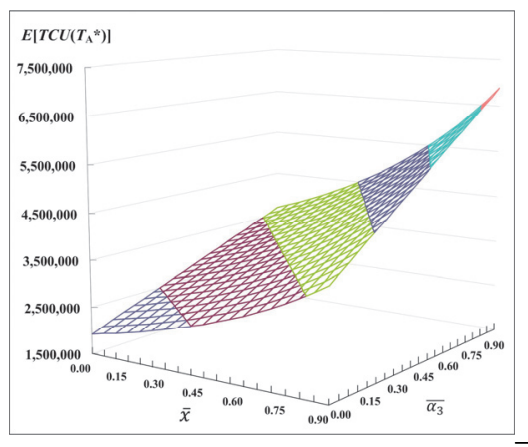

Fig. 10. Combined impacts of variations in $\bar{x}$ and $\overline{\alpha_{3}}$ on $E\left[T C U\left(T_{\mathrm{A}}^{*}\right)\right]$.

Fig. 10 depicts the analytical results on combined impacts of variations in average random scrap rate $\bar{x}$ and average added expedited unit cost $\overline{\alpha_{3}}$ on the optimal system cost $E\left[T C U\left(T_{\mathrm{A}}{ }^{*}\right)\right]$. It is noted that $E\left[T C U\left(T_{\mathrm{A}}{ }^{*}\right)\right]$ raises drastically, as both $\bar{x}$ and $\overline{\alpha_{3}}$ increase.

\section{Conclusions}

This paper has aimed to decide the most economic cycle time for a multiproduct FPR-based inventory system featuring the expedited rate and scraps. We cautiously constructed a mathematical model to examine and resolve the problem, and employed a numerical illustration to exhibits applicability of our investigation outcome. Other than obtaining the most economic cycle length for the problem, the core contribution of this research has also included revealing the individual and combined impact(s) of key factors to the problem (refer to section four), which have never been exposed until now. Examining the effect of random demands of multiproduct on the same system shall be an interesting area for future research.

\section{Acknowledgements}

Authors truthfully express gratitude to Ministry of Science and Technology of Taiwan for supporting this research (under grant no. MOST 106- 2410-H-324-003).

\section{References}

Absi, N. \& Kedad-Sidhoum, S. (2009). The multi-item capacitated lot-sizing problem with safety stocks and demand shortage costs. Computers and Operations Research, 36(11), 2926-2936.

Al-Bahkali, E.A., \& Abbas, A.T. (2018). Failure analysis of vise jaw holders for hacksaw machine. Journal of King Saud University-Engineering Sciences, 30(1), 68-77.

Ameen, W., AlKahtani, M., Mohammed, M.K., Abdulhameed, O., \& El-Tamimi, A.M. (2018). Investigation of the effect of buffer storage capacity and repair rate on production line efficiency. Journal of King Saud University - Engineering Sciences, 30(3), 243-249

Bylka, S., \& Rempala, R. (2001). Multiproduct lot sizing for finite production rate. International Journal of Production Economics, 71(1-3), 305-315.

Chakraborty, T., Chauhan, S.S., \& Giri, B.C. (2013). Joint effect of stock threshold level and production policy on an unreliable production environment. Applied Mathematical Modelling, 37(10-11), 6593-6608.

Cheung, K.L., \& Hausman, W.H. (1997). Joint determination of preventive maintenance and safety stocks in an unreliable production environment. Naval Research Logistics, 44(3), 257-272.

Chiu, Y-S.P., Lin, H-D., Tseng, C-T., \& Chiu, S.W. (2016a). Determining cycle time for a multiproduct FPR model with rework and an improved delivery policy by alternative approach. International Journal for Engineering Modelling, 29(1-4), 27-36.

Chiu, Y-S.P., Hsieh, Y-T., Kuo, J-S., \& Chiu, S.W. (2016b). A delayed differentiation multi-product FPR model with scrap and a multi-delivery policy-I: Using single-machine production scheme. International Journal for Engineering Modelling, 29(1-4), 37-52.

Chiu, Y-S.P., Lin, H-D., Wu, M-F., \& Chiu, S.W. (2018a). Alternative fabrication scheme to study effects of rework 
of nonconforming products and delayed differentiation on a multiproduct supply-chain system. International Journal of Industrial Engineering Computations, 9(2), 235-248.

Chiu, S.W., Wu, H-Y., Chiu, Y-S.P., \& Hwang, M-H. (2018b). Exploration of finite production rate model with overtime and rework of nonconforming products. Journal of King Saud University-Engineering Sciences, 30(3), 224-231.

Chiu, Y-S.P., Chen, H-Y., Chiu, T., \& Chiu, S.W. (2018c). Incorporating flexible fabrication rate and random scrap into a FPR-based supply-Chain system. Economic Computation and Economic Cybernetics Studies and Research, 52(2), 157-174.

Clausen, J. \& Ju, S. (2006). A hybrid algorithm for solving the economic lot and delivery scheduling problem in the common cycle case. European Journal of Operational Research, 175(2), 1141-1150.

Eroglu, A., \& Ozdemir, G. (2007). An economic order quantity model with defective items and shortages. International Journal of Production Economics, 106(2), 544-549.

Fergany, H.A. (2016). Probabilistic multi-item inventory model with varying mixture shortage cost under restrictions. SpringerPlus, 5(1), art. no. 1351.

Gallego, G. (1993). Reduced production rates in the economic lot scheduling problem. International Journal of Production Research, 31(5), 1035-1046.

Glock, C.H. (2013). The machine breakdown paradox: How random shifts in the production rate may increase company profits. Computers and Industrial Engineering, 66(4), 1171-1176.

Jawla, P. \& Singh, S.R. (2016). Multi-item economic production quantity model for imperfect items with multiple production setups and rework under the effect of preservation technology and learning environment. International Journal of Industrial Engineering Computations, 7(4), 703-716.

Kaylani, H., Almuhtady, A., \& Atieh, A.M. (2016). Novel approach to enhance the performance of production systems using lean tools. Jordan Journal of Mechanical and Industrial Engineering, 10(3), 215-229.

Khanna, A., Kishore, A., \& Jaggi, C.K. (2017). Strategic production modeling for defective items with imperfect inspection process, rework, and sales return under two-level trade credit. International Journal of Industrial Engineering Computations, 8(1), 85-118.

Kumar, S., Goyal, A., \& Singhal, A. (2017). Manufacturing flexibility and its effect on system performance. Jordan Journal of Mechanical and Industrial Engineering, 11(2), 105-112.

Larsen, C. (1997). Using a variable production rate as a response mechanism in the economic production lot size model. Journal of the Operational Research Society, 48(1), 97-99.

Liu, Y., Wu, H., Hou, J., Wei, C., \& Ren, W. (2017). An injection/production rate allocation method applied for polymer-surfactant flooding. Journal of Engineering Research, 5(2), 250-267.

Ma, W-N., Gong, D-C., \& Lin, G.C. (2010). An optimal common production cycle time for imperfect production processes with scrap. Mathematical \& Computer Modelling, 52(5-6), 724-737.

Majumder, P., Mondal, S.P., Bera, U.K., \& Maiti, M. (2016). Application of Generalized Hukuhara derivative approach in an economic production quantity model with partial trade credit policy under fuzzy environment. Operations Research Perspectives, 3, 77-91.

Makis, V. (1998). Optimal lot sizing and inspection policy for an EMQ model with imperfect inspections. Naval Research Logistics, 45(2), 165-186.

Muller, A., \& Clarkson, C. (2016). Identifying major transitions in the evolution of lithic cutting edge production rates. PLoS ONE, 11(12), art. no. e0167244.

Nahmias, S. (2009). Production \& Operations Analysis, McGraw-Hill Inc, New York.

Neidigh, R.O. \& Harrison, T.P. (2010). Optimising lot sizing and order scheduling with non-linear production rates. International Journal of Production Research, 48(8), 2279-2295.

Pearce, A., Pons, D., \& Neitzert, T. (2018). Implementing lean-Outcomes from SME case studies. Operations Research Perspectives, 5, 94-104.

Pellerin, R., Sadr, J., Gharbi, A., \& Malhamé, R. (2009). A production rate control policy for stochastic repair and remanufacturing systems. International Journal of Production Economics, 121(1), 39-48.

Rakyta, M., Fusko, M., Herčko, J., Závodská, L., \& Zrnić, N. (2016). Proactive approach to smart maintenance and logistics as a auxiliary and service processes in a company. Journal of Applied Engineering Science, 14(4), 433-442.

Razmi, J., Kazerooni, M.P., \& Sangari, M.S. (2016). Designing an integrated multi-echelon, multi-product and multi-period supply chain network with seasonal raw materials. Economic Computation and Economic Cybernetics Studies and Research, 50(1), 273-290.

Rezazadeh, H., \& Khiali-Miab, A. (2017). A two-layer genetic algorithm for the design of reliable cellular manufacturing systems. International Journal of Industrial Engineering Computations, 8(3), 315-332. 
Rosenblatt, M.J., \& Lee, H.L. (1986). Economic production cycles with imperfect production processes. IIE Transactions, 18, 48-55.

Rosenblatt, M.J. \& Rothblum, U.G. (1990). On the single resource capacity problem for multi-item inventory systems. Operations Research, 38(4), 686-693.

Shakoor, M., Abu Jadayil, W., Jabera, N., \& Jaber, S. (2017). Efficiency assessment in emergency department using lean thinking approach. Jordan Journal of Mechanical and Industrial Engineering, 11(2), 97-103.

Song, J-S. (1998). On the order fill rate in a multi-item, base-stock inventory system. Operations Research, 46(6), $831-845$.

Taft, E.W. (1918). The most economical production lot. Iron Age, 101, 1410-1412.

Taleizadeh, A.A., Jalali-Naini, S.G., Wee, H-M., \& Kuo, T-C. (2013). An imperfect multi-product production system with rework. Scientia Iranica, 20(3), 811-823.

Villeda, R., Dudek, R., \& Smith, M.L. (1988). Increasing the production rate of a just-in-time production system with variable operation times. International Journal of Production Research, 26(11), 1749-1768.

Vujosevic, M., Makajic-Nikolic, D., \& Pavlovic, P. (2017). A new approach to determination of the most critical multi-state components in multi-state systems. Journal of Applied Engineering Science, 15(4), 401-405.

Wolisz, A. (1984). Production rate optimization in a two-stage system with finite intermediate storage. European Journal of Operational Research, 18(3), 369-376.

Zahedi, Z., Ari Samadhi, T.M.A., Suprayogi, S., \& Halim, A.H. (2016). Integrated batch production and maintenance scheduling for multiple items processed on a deteriorating machine to minimize total production and maintenance costs with due date constraint. International Journal of Industrial Engineering Computations, 7(2), 229-244.

Zahorik, A., Thomas, L.J., \& Trigeiro, W.W. (1984). Network Programming Models for Production Scheduling in Multi-stage, Multi-item Capacitated Systems. Management Science, 30(3), 308-325.

Zhang, D., Zhang, Y., \& Yu, M. (2016). A machining process oriented modeling approach for reliability optimization of failure-prone manufacturing systems. Journal of Engineering Research, 4(3), 128-143.

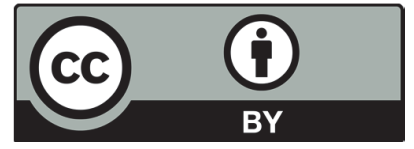

(C) 2019 by the authors; licensee Growing Science, Canada. This is an open access article distributed under the terms and conditions of the Creative Commons Attribution (CCBY) license (http://creativecommons.org/licenses/by/4.0/). 